\title{
AVALIAÇÃO TÉCNICA DO TRATOR FLORESTAL ARRASTADOR "SKIDDER" COM DIFERENTES TIPOS DE RODADOS NA EXTRAÇÃO DE MADEIRA EM POVOAMENTOS DE PINUS ${ }^{1}$
}

Eduardo da Silva Lopes² ${ }^{2}$ Jacks Willer Prado Missel ${ }^{3}$, Andréa Nogueira Dias²e Nilton César Fiedler ${ }^{4}$

\begin{abstract}
RESUMO - Este trabalho teve como principal objetivo a avaliação técnica das atividades de extração de madeira usando tratores florestais arrastadores skidders equipados com rodado de pneus e com rodado de pneus recoberto com semi-esteiras. A avaliação técnica consistiu em determinar os índices de produtividade da operação de extração da madeira por meio de um estudo de tempos e movimentos, em que a operação foi dividida em fases do ciclo de trabalho. Foram determinadas as produtividades das máquinas em diferentes situações de distâncias de extração e declividades de terreno. Os resultados indicaram que o tempo médio do ciclo operacional do skidder com rodado de pneus foi 7,1\% menor em relação ao skidder de pneus recobertos por esteiras, o que explicado se pela maior eficiência dos pneus sobre a superfície do terreno. O skidder de pneus apresentou melhor eficiência na situação de declividade entre 10 e $20 \%$, devido à maior agilidade do rodado de pneus e capacidade em desenvolver maior velocidade, enquanto o skidder com rodado de pneus recoberto por esteiras apresentou velocidade operacional constante. Em declividade acima de 20\%, o skidder de pneus recoberto com esteiras realizou normalmente o arraste da madeira, enquanto o skidder de pneus não entrou em operação devido à elevada patinagem dos pneus e diminuição da capacidade de tração.
\end{abstract}

Palavras-chave: Colheita de madeira, extração florestal e skidder.

\section{TECHNICAL EVALUATION OF A SKIDDER WITH DIFFERENT WHEELED TYPES IN LOG EXTRACTION ACTIVITIES OF PINE PLANTATION}

\begin{abstract}
The objective of this study was to evaluate technical log extraction activities using a skidder with tires and a skidder with tracks over the tires. Technical evaluation consisted in determining log extraction productivity indexes based on motion and time study, in which the extraction activities were grouped into work cycle phases. Machine productivity was determined in different extraction distances and slope degree situations. The results showed that the operational cycle average time of the tire skidder was $7.1 \%$ smaller that the skidder with tracks over the tires, explained by the efficiency of the tires over terrain surface. In slopes above $20.0 \%$, the skidder with tracks over the tires performed the log extraction activities normally, while the tire skidder was unable to operate due to high tire skid and traction capacity decrease.
\end{abstract}

Keywords: Timber harvesting, wood extraction and skidder.

\footnotetext{
${ }^{1}$ Recebido em 07.06.2006 e aceito para publicação em 07.11.2006.

${ }^{2}$ Departamento de Engenharia Florestal da Universidade Estadual do Centro Oeste (UNICENTRO). E-mail: <eslopes@ irati.unicentro.br>.

${ }_{3}^{3}$ Departamento de Engenharia Florestal da UNICENTRO-Programa de Iniciação Científica. E-mail: <jackmissel@ yahoo.com.br>.

${ }^{4}$ Departamento de Engenharia Florestal da Universidade Federal do Espírito Santo (UFES). E-mail: <fiedler@ pesquisador.cnpq.br>.
} 


\section{INTRODUÇÃO}

A mecanização das operações de colheita de madeira intensificou a partir da década de 1990, devido à redução da dependência da mão-de-obra, melhoria das condições de trabalho, necessidade por parte das indústrias de um fornecimento regular e cada vez maior de madeira e, principalmente, pela necessidade de redução dos custos de produção, implicando aumento no rendimento das operações (BRAMUCCI e SEIXAS, 2002).

Considerando que as operações de colheita e transporte de madeira representam $50 \%$, ou mais, do total dos custos finais da madeira posta na fábrica (MOREIRA et al., 2004), o aperfeiçoamento das técnicas que tornem a colheita e o beneficiamento da madeira mais racionais torna-se cada vez mais necessário (MINETTE et al., 2004). Isso implica aumento no rendimento das operações de colheita florestal, elevando o nível de produtividade e contribuindo para o aumento na competitividade das empresas florestais (BRAMUCCI e SEIXAS, 2002; SILVA et al., 2003).

A extração é uma das etapas mais complexas da colheita de madeira, haja vista que o custo dessa etapa é influenciado por diversos fatores, como o nível de experiência e habilidade do operador, condições do povoamento, características do terreno, distância de extração, desempenho da máquina etc. Adesconsideração de algum desses fatores poderá resultar em problemas operacionais e ineficiência da operação (CONWAY, 1976; SALMERON, 1980; MACHADO, 1984).

Os "skidders" são tratores florestais articulados que realizam o arraste das árvores da área de corte até a margem da estrada ou pátio intermediário, podendo o material rodante ser de pneus, semi-esteiras ou esteiras. Souza et al. (2002) citaram os principais problemas relacionados à operação de arraste de madeira, como a compactação do solo, passagem da máquina sobre as pilhas de árvores e arraste de material para a margem do talhão, bem como a perda de rendimento em função das condições do solo, do povoamento e do clima.

Essas condições têm levado ao uso freqüente de máquinas com rodados de semi-esteiras ou esteiras, principalmente no arraste de madeira em condições de solos úmidos e em relevos acidentados (BYGDÉN et al., 2003). O uso dessas máquinas tem reduzido significativamente a compactação e os distúrbios ao solo, permitindo, ainda, o acesso da máquina em áreas declivosas, onde muitas vezes o rodado de pneus não é capaz de atuar. Porém, como desvantagem, o rodado de esteiras possui menor mobilidade sobre a superfície do solo, comprometendo o desempenho da máquina e a produtividade da operação.

O objetivo desta pesquisa foi analisar tecnicamente o desempenho de tratores florestais arrastadores "skidders" com rodados de pneus e com rodados de pneus recobertos por esteiras na extração de madeira em povoamentos de pinus taeda.

\section{MATERIAIS E MÉTODOS}

\section{1. Área de estudo}

Este trabalho foi conduzido nas áreas florestais da empresa Battistella Florestal., no Município de Rio Negrinho, em Santa Catarina, entre os paralelos $26^{\circ} 15^{\prime} 16^{\prime \prime}$ $\mathrm{S}$ de latitude e 49\%31'06" W de longitude e a $790 \mathrm{~m}$ de altitude. O clima característico da região é o $\mathrm{CFb}$ (Köppen), com precipitação média anual entre 1.300 e $1.500 \mathrm{~mm}$ e temperatura média anual de $16^{\circ} \mathrm{C}$. Os dados foram coletados durante o período de abril a julho de 2005, nos reflorestamentos da empresa que eram constituídos por plantios de Pinus taeda, cuja colheita era realizada aos 20 anos de idade em regime de corte raso.

\subsection{Descrição dos equipamentos}

Nesta pesquisa foram utilizados dois tratores florestais arrastadores "skidders", da marca Caterpillar, modelo 545 , com tração $4 \times 4$, potência nominal de $225 \mathrm{hp}$, equipados com rodados de pneus e garra de capacidade de $1,5 \mathrm{~m}^{2}$. A primeira máquina possuía sistema rodante de pneus originais de fábrica, enquanto na segunda máquina foram instaladas sobre os pneus quatro semi-esteiras da marca Eco Wheel Track, da Olofsfors (Figura 1).

\subsection{Coleta de dados}

Inicialmente foi realizado um estudo-piloto da operação de arraste, buscando-se definir o número de observações necessárias para proporcionar um erro de amostragem máximo de 5\%, segundo a metodologia proposta por Barnes (1968), por meio da seguinte expressão:

$$
\mathrm{n} \geq \frac{\mathrm{t}^{2} \times \mathrm{CV}^{2}}{\mathrm{E}^{2}}
$$

em que $\mathrm{n}=$ número mínimo de ciclos necessários; $\mathrm{t}$ = valor de $\mathrm{t}$, para o nível de probabilidade desejado e $(n-1)$ graus de liberdade; $C V=$ coeficiente de variação, em porcentagem; e $\mathrm{E}=$ erro admissível, em porcentagem. 


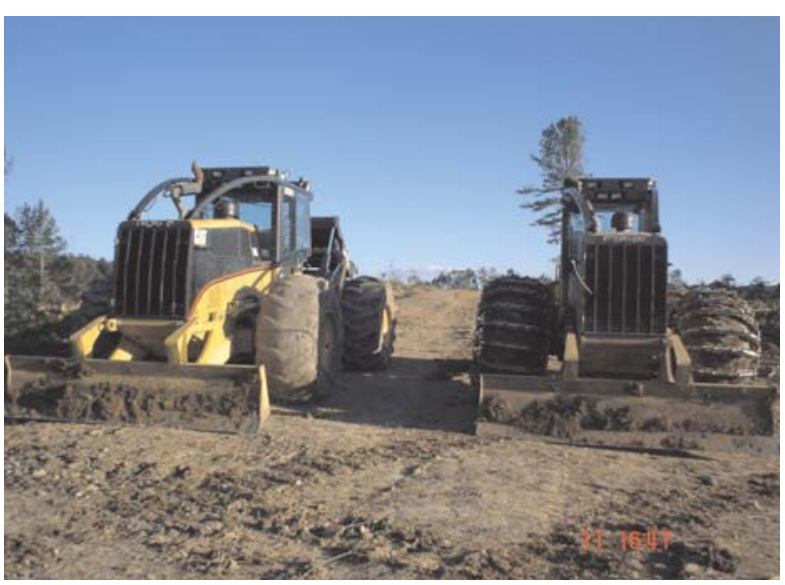

Figura 1 - Skidder de pneus e skidder de pneus recobertos por esteiras avaliadas no trabalho.

Figure 1 -Skidder with tires and skidder with tracks over the tires evaluated in this work.

No estudo de tempos e movimentos foram coletados dados de 715 ciclos operacionais, atendendo à exigência do estudo-piloto.

\subsection{Análise estatística}

A amostragem contemplou cinco classes de distâncias de extração e três classes de declividades do terreno. Foi ajustado um modelo de regressão de cada classe de declividade e tipo de rodado (pneu e esteira), a fim de verificar a relação entre a variável dependente (tempo do ciclo operacional) e a variável independente (distância de extração), conforme expressão abaixo:

$$
Y=\beta_{o}+\beta_{I} x
$$

em que:

$\mathrm{Y}=$ tempo do ciclo operacional ( $\mathrm{s}) ; \mathrm{X}=$ distância de extração $(\mathrm{m})$; e $\beta_{0}, \beta_{1}=$ coeficientes.

Para avaliação estatística das equações, foram utilizados os coeficientes de determinação $\left(\mathrm{R}^{2}\right)$, a significância da equação e dos coeficientes. Além disso, compararam-se graficamente a tendência da curva de produtividade observada nas diferentes classes de declividades e a produtividade estimada por meio das análises de regressão.

\subsection{Análise técnica}

A análise técnica dos skidders equipados com os sistemas rodantes de pneus e semi-esteiras foi realizada com base nos seguintes parâmetros:

\subsubsection{Estudo de Tempo e Movimentos}

Foi realizado um estudo de tempos e movimentos da operação de arraste, por meio do método de tempos contínuos conforme metodologia descrita por Barnes (1977). Os elementos parciais que compuseram o ciclo operacional dos "skidders" foram: VV - viagem sem carga: correspondeu ao tempo consumido pela máquina para se deslocar da estrada ao interior do talhão próximo ao feixe de árvores a ser arrastado; MC - manobra e carregamento: correspondeu ao tempo consumido pela máquina para a realização das manobras, aproximação e carregamento do feixe de árvores; VC - viagem com carga: correspondeu ao tempo consumido pela máquina no arraste do feixe de árvores do interior do talhão até a margem da estrada; DM - descarregamento e manobra: correspondeu ao tempo consumido pela máquina para a realização, quando necessário, das manobras e descarregamento do feixe de árvores na margem da estrada; e INT - interrupções operacionais e não-operacionais: foram registrados todos os tempos em que a máquina não estava realizando as atividades anteriormente mencionadas.

Para a coleta de dados foi utilizado um cronômetro centesimal, uma trena, estacas, planilhas específicas e um rádio receptor.

\subsubsection{Produtividade}

A produtividade do "skidder" de pneus e semiesteiras foi determinada por meio dos dados do inventário realizado preliminarmente, onde se obteve o volume médio por árvore, sendo esse multiplicado pelo número de árvores arrastada pelo skidder em cada ciclo operacional e, em seguida, dividido pelas horas efetivamente trabalhadas, conforme a expressão:

$$
\operatorname{Prod}\left(\mathrm{m}^{3} / \mathrm{he}\right)=\frac{\text { número de arvores } \times \text { volume por árvore }}{\text { horas efetivamen te trabalhadas }}
$$
em que:

número de árvores = este número foi obtido através de um censo completo realizado inicialmente em cada parcela; volume por árvore = é o volume médio por árvore dentro de cada bloco, sendo este dado obtido através do inventário da área; horas efetivamente trabalhadas $=$ são as horas efetivas de trabalho gastas por máquina em cada parcela experimental, obtidas por meio do estudo de tempos e movimentos e da coleta das horas efetivas trabalhadas em cada parcela.

R. Árvore, Viçosa-MG, v.31, n.6, p.1053-1061, 2007 


\subsection{Fatores de influência no desempenho das máquinas}

\subsubsection{Espécie florestal}

Em toda a área estudada, a espécie florestal extraída foi o Pinus taeda, considerado constante em todos os tratamentos.

\subsubsection{Volume médio por árvore}

Obtido por meio de inventário florestal pré-corte, expresso em $\mathrm{m}^{3} \mathrm{com}$ casca, sendo considerados diferentes em cada tratamento alocado na área de estudo.

\subsubsection{Solo}

O tipo de solo predominante da região é o Cambissolo Álico, textura argilosa, fase floresta subtropical perenifólia, relevo ondulado e forte ondulado, substrato siltitos e folhelhos, sendo considerado constante em toda a área de estudo.

\subsubsection{Operadores}

Foram utilizados no estudo dois operadores com experiência na operação de skidder e que apresentavam desempenho técnico semelhante na operação de extração florestal.

\subsubsection{Distância de extração}

A distância de extração (DE) considerada foi a distância percorrida pela máquina carregada entre a base do feixe de árvores formada no interior do talhão e a margem da estrada, onde o feixe foi depositado para processamento. A distância de extração foi estratificada em cinco níveis: I: $\mathrm{DE} \leq 50 \mathrm{~m}$; II: $50<$ $\mathrm{DE} \leq 100 \mathrm{~m}$; III: $100<\mathrm{DE} \leq 150 \mathrm{~m}$; IV: $150<\mathrm{DE} \leq 200$ $\mathrm{m} ;$ e V: $200<\mathrm{DE} \leq 250 \mathrm{~m}$.

\subsubsection{Declividade do Terreno}

A declividade do terreno (DL) foi considerada como a inclinação das trilhas de arraste, determinada por meio de clinômetro e estratificada em três níveis: I: $0<$ DL $\leq 10 \%$; II: $10<$ DL $\leq 20 \%$; III: $20<$ DL $\leq 30 \%$; e IV: $>30 \%$.

\section{RESULTADOS E DISCUSSÃO}

\subsection{Estudo de tempos e movimentos}

A constituição média dos elementos do ciclo operacional do "skidder" de pneus e de semi-esteiras analisados é mostrada na Figura 2. Esses valores correspondem ao ciclo operacional de viagem sem carga, manobra e carregamento, viagem com carga, manobra e descarregamento e interrupções operacionais e nãooperacionais.

Os elementos parciais que consumiram a maior parte do tempo do ciclo operacional do "skidder" de pneus foram a manobra e carregamento e a viagem com carga, com 25,2 e $24,8 \%$ do tempo total do ciclo operacional, respectivamente. Para o "skidder" de semiesteiras, os elementos que consumiram a maior parte do tempo do ciclo foram a viagem com carga com $27,9 \%$, seguido pela manobra e carregamento com $25,2 \%$ do tempo total. Os elementos viagem sem carga e manobra e descarregamento veio em seguida, abrangendo 22,4 e $20,6 \%$ para o "skidder" de pneu e 22,2 e $17,6 \%$ para o "skidder" de semi-esteiras, respectivamente.
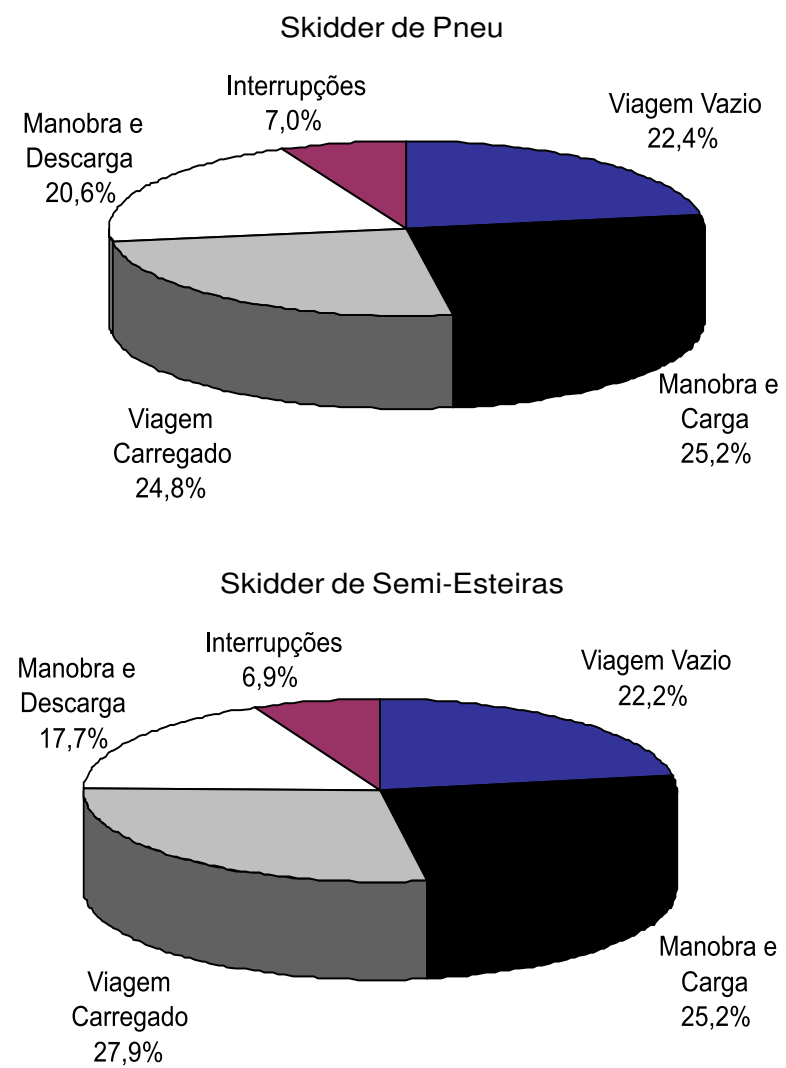

Figura 2 - Composição porcentual do ciclo operacional do skidder de pneus e do skidder de pneus recobertos por esteiras.

Figure 2-Percent composition of the operational cycle of the skidder with tires and skidder with tracks over the tires. 
As interrupções abrangeram 7,0 e 6,9\% do tempo total do ciclo operacional dos "skidders" de pneu e de semi-esteiras, respectivamente. As interrupções operacionais mais observadas foram: limpeza do estaleiro, deslocamento entre talhão e abastecimento, enquanto a interrupção não-operacional foi a parada para supervisão e realização de refeição.

O tempo médio do ciclo operacional do "skidder" de pneus foi $7,1 \%(2,6 \mathrm{~min})$ menor que do "skidder" de semi-esteiras (2,8 $\mathrm{min}$ ), proporcionando um rendimento $12,3 \%$ superior em relação ao volume arrastado por hora efetiva. Essa diferença se deveu à maior mobilidade do rodado de pneus em relação ao rodado com semiesteiras, porém essa diferença não foi considerada significativa devido à baixa distância média de arraste (56,8 $\mathrm{m})$ encontrada nas áreas onde foi realizado este estudo. Em distâncias maiores, é esperado que ocorra uma diferença significativa entre o tempo do ciclo operacional dos "skidders" de pneus e de semi-esteiras, influenciando diretamente o rendimento da operação.

\subsection{Estimativa da produtividade}

Inicialmente, procuraram-se identificar as diferenças de produtividade entre o "skidder" de pneus e de semiesteiras nas diferentes classes de declividades estudadas. Como pode ser observado na Figura 3, em ambas as situações a produtividade média do "skidder" de pneus e de semi-esteiras decresceu à medida que se aumentou a distância de arraste, devido ao maior tempo consumido para completar o ciclo operacional.

Analisando a situação de declividade entre 0 e $10 \%$, verificou-se que o "skidder" de pneus apresentou produtividade superior em relação ao "skidder" com semi-esteiras nas menores distâncias de extração, enquanto nas maiores distâncias a produtividade do "skidder" de semi-esteiras foi superior. Esse comportamento pode ser explicado pela maior mobilidade do rodado de pneus no arraste em pequenas distâncias de extração, enquanto nas maiores distâncias o rodado de semi-esteira apresentou maior capacidade de tração e menor patinagem comparada com o rodado de pneus, proporcionando, com isso, um desempenho constante da máquina durante todo o ciclo operacional. Na situação de declividade entre 10 e $20 \%$, verificou-se que a produtividade média do "skidder" de pneus foi ligeiramente superior ao "skidder" de semi-esteiras, explicada pela maior facilidade desse tipo de rodado em desempenhar maior velocidade operacional no arraste do feixe de árvores, principalmente em situações de declive. No entanto, nas maiores distâncias de arraste o "skidder" de semi-esteiras apresentou melhor desempenho. Portanto, espera-se que em áreas mais declivosas e em maiores distâncias de arraste o "skidder" de semi-esteiras tenha um desempenho melhor, explicado pela sua velocidade constante e menor índice de patinagem ao longo do ciclo operacional.
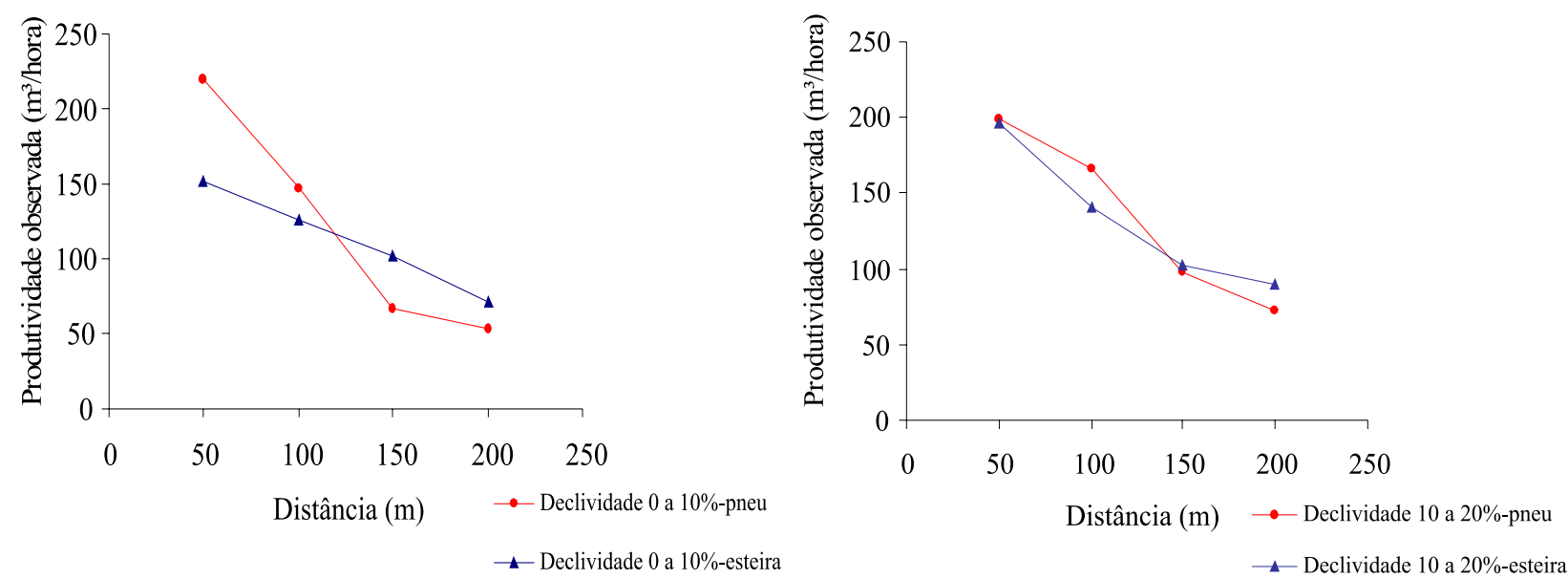

Figura 3 - Produtividade observada do skidder de pneus e do skidder de pneus recobertos por esteira, em função de diferentes distâncias de extração e classes de declividade.

Figure 3 - Observed productivity of the skidder with tires and skidder with tracks over the tires as a function of different extraction distances and slope degrees.

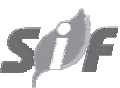

R. Árvore, Viçosa-MG, v.31, n.6, p.1053-1061, 2007 
Em função das diferenças de produtividades médias obtidas em cada distância de arraste, optou-se por estimar equações individuais por tipo de rodado e por classe de declividade.

\subsubsection{Skidder de pneus}

A Figura 4 ilustra a tendência dos dados de produtividade observada do "skidder" com rodado de pneus para cada classe de declividade e distância de extração.

As equações geradas que estimam o tempo do ciclo operacional do "skidder" de pneus em função da distância de extração são representadas no Quadro 1 e na Figura 5, com os respectivos coeficientes de determinação $\left(\mathrm{R}^{2}\right)$.

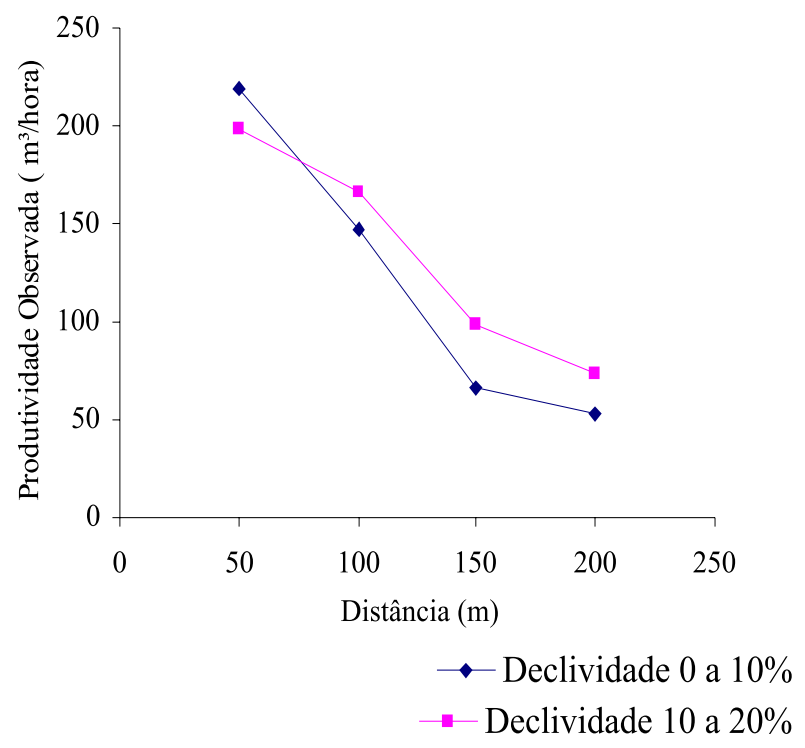

Figura 4 - Produtividade média de arraste com skidder de pneus em função da distância de extração e classes de declividade.

Figure 4-Average skidding productivity of skidder with tires as a function of the extraction distance and slope degrees.
As equações utilizadas neste estudo foram consideradas aceitáveis para estimar o tempo do ciclo operacional do "skidder" de pneus nas diferentes classes de declividade e distância de extração. As equações representadas no Quadro 2 foram utilizadas para estimar indiretamente a produtividade média do "skidder" de pneus (Figura 6), considerando-se um volume médio observado nos feixes de árvores igual a $5,7 \mathrm{~m}^{3}$, nas duas classes de declividades.
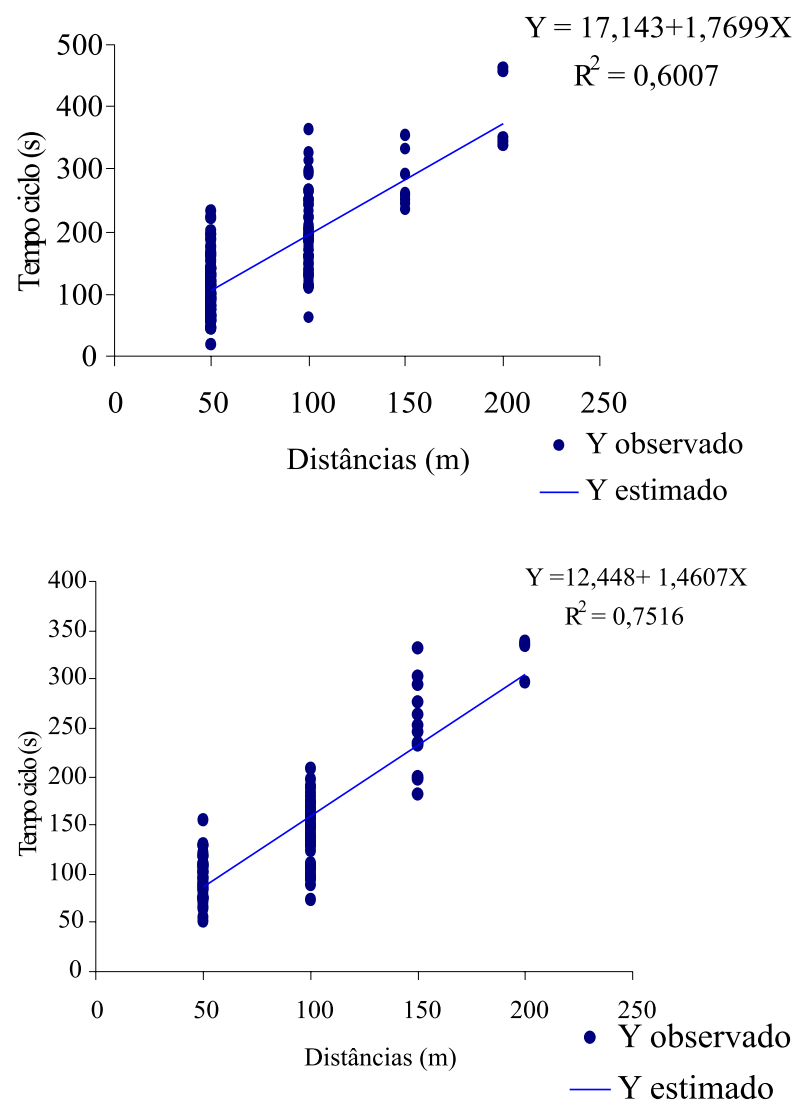

Figura 5 - Valores observados e reta da regressão do skidder de pneus, nas classes de declividade 0 a $10 \%$ (a) e 10 a $20 \%$ (b).

Figure 5 - Observed values and regression line to skidder with tires on slope degree 0 to $10 \%$ (a) and 10 to $20 \%(b)$.

Quadro 1 - Tempo estimado do ciclo operacional do skidder de pneus, em função da distância de extração Table 1 - Operational cycle estimate time of the skidder with tires as a function of the extraction distance

\begin{tabular}{ccccc}
\hline Classe de declividade $(\%)$ & Equação & $\mathrm{R}^{2}$ & $\mathrm{~F}$ & $\mathrm{~N}$ \\
\hline a 10 & $\mathrm{Y}=12,4482^{*}+1,4607^{* *}(\mathrm{X})$ & 0,75 & $290,39^{* * *}$ & 195 \\
10 a 20 & $\mathrm{Y}=17,1426^{*}+1,7699^{* *}(\mathrm{X})$ & 0,60 & $290,41^{* *}$ & 98 \\
\hline
\end{tabular}

$\mathrm{Y}=$ Tempo do ciclo $(\mathrm{s}) ; \mathrm{X}=$ distância de extração $(\mathrm{m})$. * significativo a $5 \%$ de probabilidade. ** significativo a $1 \%$ de probabilidade.

R. Árvore, Viçosa-MG, v.31, n.6, p.1053-1061, 2007 
Quadro 2 - Tempo estimado do ciclo operacional do skidder de pneus recobertos por esteiras, em função da distância de extração e das classes de declividade

Table 2 - Estimated time operational cycle of the skidder with tracks over the tires as function of the differences extraction distances and slope degree

\begin{tabular}{ccccc}
\hline Classe de declividade (\%) & Equação & $\mathrm{R}^{2}$ & $\mathrm{~F}$ & $\mathrm{n}$ \\
\hline 0 a 10 & $\mathrm{Y}=15,8625^{*}+1,8203^{* *}(\mathrm{X})$ & 0,65 & $423,07^{* * *}$ & 233 \\
10 a 20 & $\mathrm{Y}=45,2816^{* *}+1,5995^{* *}(\mathrm{X})$ & 0,59 & $172,43^{* *}$ & 124 \\
20 a 30 & $\mathrm{Y}=48,6133^{* *}+1,7226^{* *}(\mathrm{X})$ & 0,64 & $88,59^{* *}$ & 53 \\
\hline
\end{tabular}

$\mathrm{Y}=$ Tempo do ciclo $(\mathrm{s}) ; \mathrm{X}=$ distância de extração $(\mathrm{m})$. * significativo a $5 \%$ de probabilidade. $* *$ significativo a $1 \%$ de probabilidade.

Como pode ser observado, o aumento na distância de extração ocasionou queda na produtividade nas duas classes de declividades. Em todas as distâncias de extração, houve uma ligeira superioridade da produtividade estimada nos locais de maior declividade (10 a 20\%), não apresentando, como nos dados observados, maior produtividade em distâncias menores que $50 \mathrm{~m}$. Nesse caso, não foi estimada a produtividade na declividade entre 20 e $30 \%$, pois nessa situação não ocorreu o arraste de madeira com o "skidder" de pneus.

\subsubsection{Skidder de semi-esteiras}

Na Figura 7 são mostradas as tendências dos dados de produtividade média observada no "skidder" com rodado de semi-esteiras em cada classe de declividade e distância de extração.

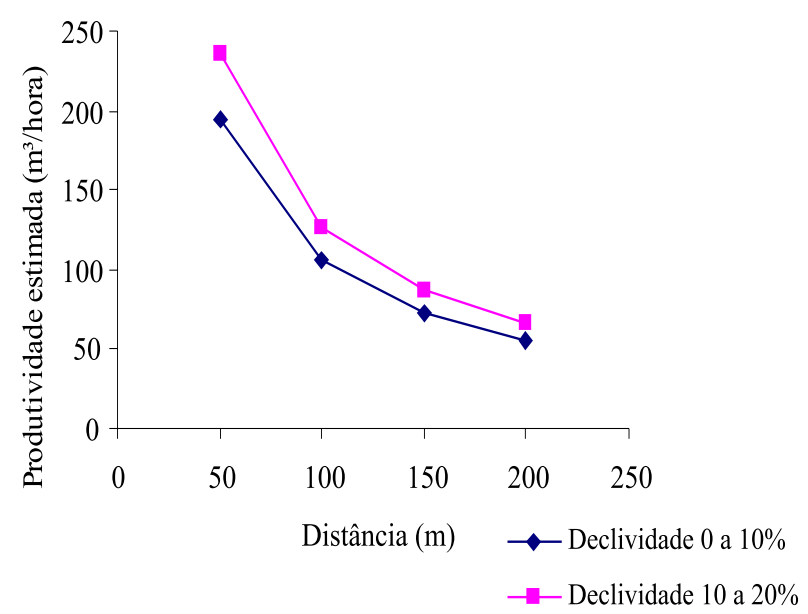

Figura 6 - Produtividade média estimada do skidder de pneu em função de diferentes distâncias de extração e classes de declividade.

Figure 6-Estimated average productivity of the skidder with tires as function of the different extraction distances and slope degrees.

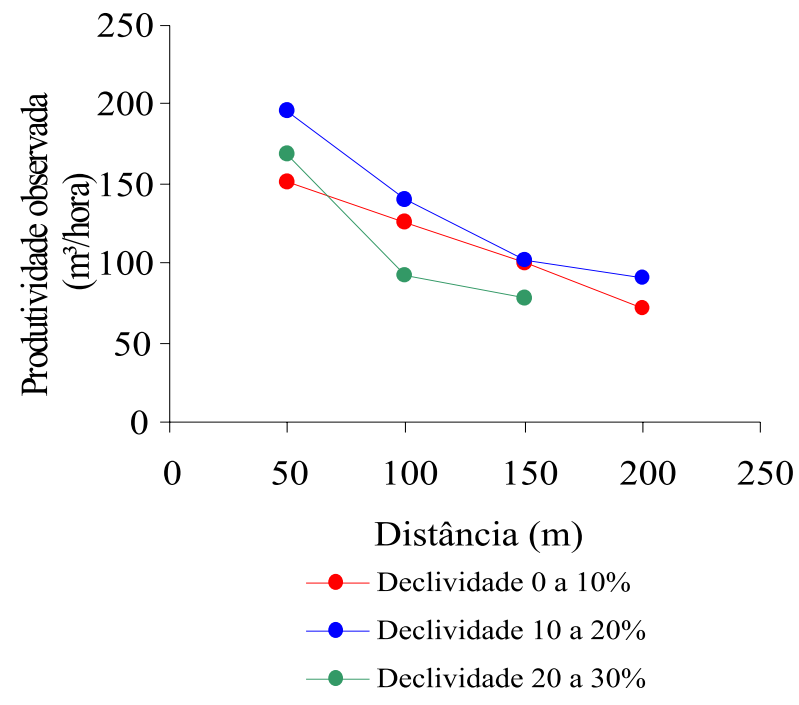

Figura 7 - Produtividade média observada do skidder de pneus recobertos por esteiras, em função de diferentes distâncias de extração e classes de declividade.

Figure 7-Observed average productivity of the skidder with tracks over the tires as function of different extraction distances and slope degrees.

Como pode ser observado, à medida que aumentou a distância de extração, a produtividade média do "skidder" de semi-esteira decresceu, devido ao aumento do ciclo operacional. Verificou-se ainda que a produtividade média do "skidder" de semi-esteiras em trerreno com classe de declividade entre 10 e $20 \%$ foi superior em relação à declividade entre 0 e $20 \%$, cujos valores observados estavam próximos entre si. Tal fato é explicado pelo maior volume médio dos feixes de árvores $\left(7,3 \mathrm{~m}^{3}\right)$ arrastados nessa situação, comparado ao volume médio dos feixes de 5,2 , e $5,5 \mathrm{~m}^{3}$ nas situações de declividade entre 0 e $10 \%$ e $20 \%$ e $30 \%$, respectivamente.

É importante ressaltar que, na situação de terreno com declividade acima de $20 \%$, a máquina com rodado de pneus não foi capaz de entrar em operação, devido ao elevado índice de patinação dos rodados e baixa

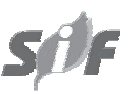

R. Árvore, Viçosa-MG, v.31, n.6, p.1053-1061, 2007 
capacidade de tração da máquina. Entretanto, a máquina com rodado equipado com semi-esteiras mostrou-se bastante eficiente, permitindo o acesso da máquina nessas condições e possibilitando o arraste das árvores. Entretanto, observou-se ainda que esse equipamento mostrou-se eficiente em uma distância máxima de 150 $\mathrm{m}$, devido à menor mobilidade do rodado de esteiras.

Tais resultados comprovaram aqueles obtidos por outros autores, destacando-se o trabalho conduzido por (BYGDÉN et al., 2003). Esses autores verificaram que máquinas com rodados de semi-esteiras ou esteiras tiveram acesso a áreas declivosas, permitindo realizar o arraste, reduzindo ainda a compactação e os distúrbios do solo.

A partir dos ajustes dos modelos, as equações para estimar o tempo do ciclo operacional do "skidder" de semi-esteiras foram geradas em função da distância de extração. Os coeficientes das equações com os

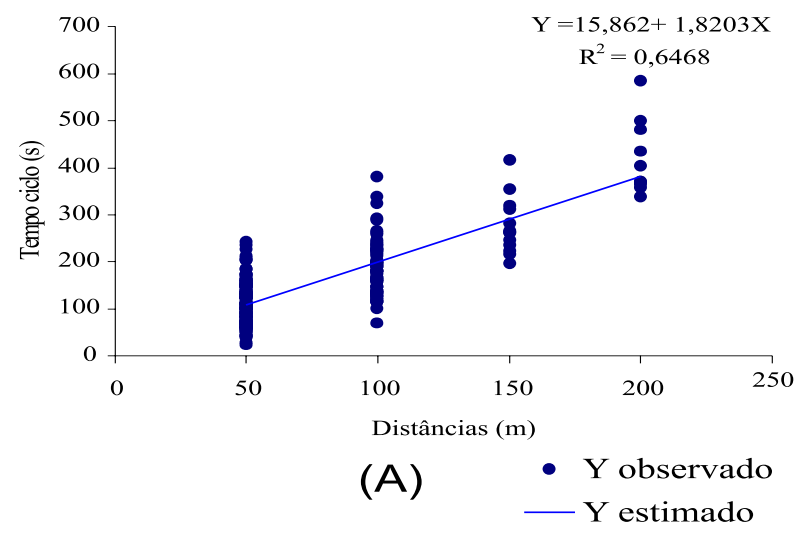

respectivos coeficientes estatísticos estão representados no Quadro 2 e na Figura 8.

As equações foram consideradas aceitáveis para estimar o tempo do ciclo operacional do "skidder" de semi-esteiras nas diferentes distâncias de extração. As equações do Quadro 2 foram utilizadas, então, para estimar, indiretamente, a produtividade média do "skidder" de semi-esteiras. Nesse caso, em cada classe de declividade: 0 a 10,10 a 20 e 20 a $30 \%$, foram empregados um volume médio dos feixes de árvores de 5,2; 7,3; e $5,5 \mathrm{~m}^{3}$, respectivamente (Figura 9).

Analisando a Figura 9, observa-se que o aumento na distância de arraste ocasionou uma queda na produtividade em todas as classes de declividades. Observa-se também maior produtividade estimada na declividade de 10 a $20 \%$, e menor produtividade na declividade de 20 a $30 \%$. Esses resultados são coerentes com a tendência encontrada nos valores observados.

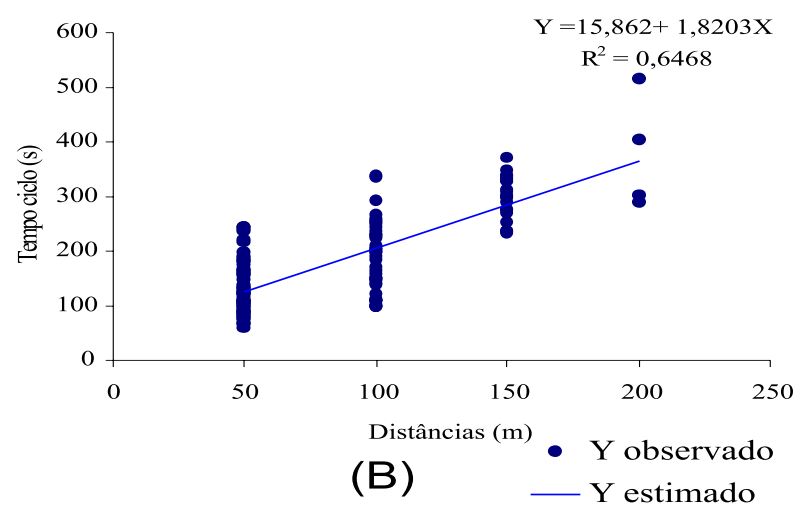

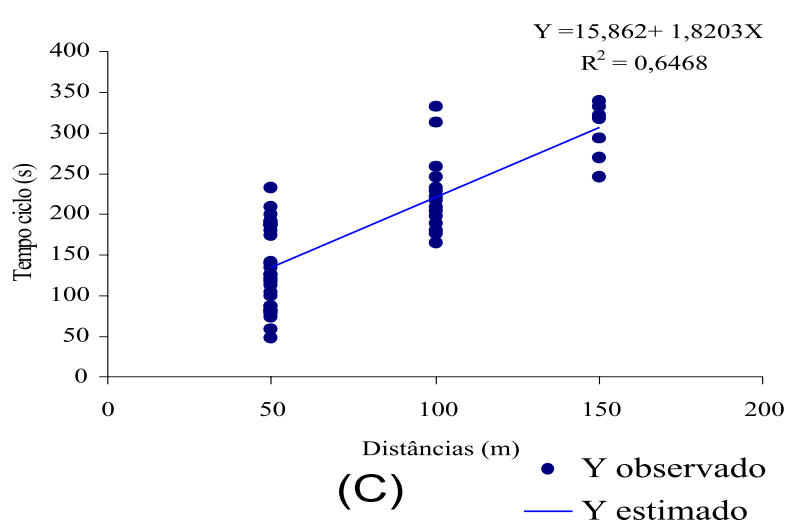

Figura 8 - Valores observados e reta de regressão do skidder de pneus recobertos por esteiras nas classes de declividade 0 a $10 \%$ (a), 10 a $20 \%$ (b) e 20 a $30 \%$ (c).

Figure 8-Observed values and regression line of skidder with tracks over the tires at slope degrees 0 to $10 \%$ (a), 10 to $20 \%(b)$ and 20 to $30 \%(c)$.

R. Árvore, Viçosa-MG, v.31, n.6, p.1053-1061, 2007 


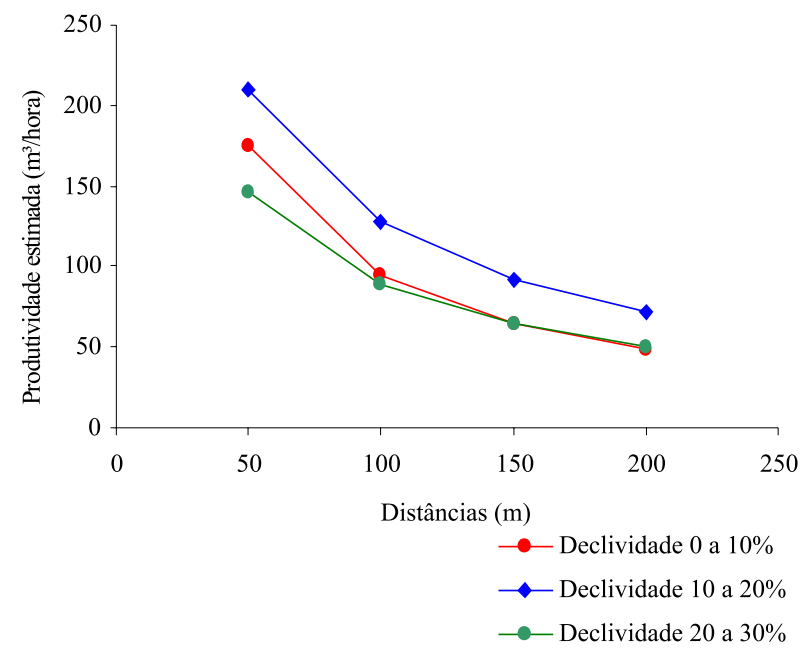

Figura 9-Produtividade média estimada do skidder de pneus recobertos por esteiras, em função de diferentes distâncias de extração e classes de declividade.

Figure 9 -Estimated average productivity of skidder with tracks over the tires in function of the different extraction distances and slope degrees.

\section{CONCLUSÕES}

Com base na análise e discussão dos resultados, as principais conclusões deste trabalho foram:

a) O tempo médio do ciclo operacional do "skidder" de pneus foi, em média, 7,1\% inferior ao "skidder" de semi-esteiras, explicado pela maior mobilidade do rodado de pneus sobre a superfície do terreno, principalmente em curtas distâncias de arraste.

b) Em todas as situações estudadas, a produtividade média das máquinas decresceu com o aumento na distância de arraste, devido ao incremento de tempo do ciclo operacional.

c) O desempenho do "skidder" de pneus foi superior na declividade entre 10 e $20 \%$, devido à maior mobilidade desse rodado e a capacidade de a máquina desenvolver maior velocidade operacional durante o arraste das árvores.

d) A produtividade média do "skidder" com rodados de pneus foi superior ao rodado de semi-esteiras, devido ao fato de a esteira possuir menor mobilidade sobre a superfície do solo, confirmando os resultados obtidos por outros autores em trabalhos semelhantes.

e) O rodado com semi-esteiras permitiu o acesso do "skidder" em terrenos com declividade acima de
$20 \%$, enquanto o "skidder" com rodado de pneus não foi capaz de atuar nessas condições, confirmando ser a esteira um acessório imprescindível na operação de arraste, principalmente em condições de terreno acidentado.

\section{REFERÊNCIAS}

BARNES, R. M. Estudos de movimentos e de tempos - projeto e medida do trabalho. São Paulo: Edgard Blucher, 1977. 635p.

BRAMUCCI, M.; SEIXAS, F. Determinação e quantificação de fatores de influência sobre a produtividade de "harvesters" na colheita florestal. Scientia Forestalis, n.62, p.62-74, 2002.

BYGDÉN, G.; WASTERLUND, I.; ELIASSON, L. Rutting and soil disturbance minimized by planning and using bogie tracks. In: SIMPÓSIO BRASILEIRO SOBRE COLHEITAE TRANSPORTE FLORESTAL, 6., 2003, Belo Horizonte. Anais... Belo Horizonte: Universidade Federal de Viçosa/ Sociedade de Investigação Florestal, 2003. p.1-9

CONWAY, S. Logging pratices; Principles of timber harvesting systems. São Francisco: Miller Freeman, 1976. 416p.

\section{MACHADO, C. C. Planejamento e controle de custos na exploração} florestal. Viçosa, MG: Universidade Federal de Viçosa, 1984. 138p.

MINETTE, L. J. et al. Análise técnica e econômica do Forwarder em três subsistemas de colheita em florestas de eucalipto. Revista Árvore, v.28, n.1, p.91-297, 2004.

MOREIRA, F. M. T. et al. Avaliação operacional e econômica do "Feller-Buncher" em dois sistemas de colheita de florestas de eucalipto. Revista Árvore, v.28, n.2, p.199-205, 2004.

SALMERON, A. A mecanização da exploração florestal. Piracicaba: IPEF, 1980. (Circular Técnico, 88).

SOUZA, A. P. et al. Perspectivas na área de colheita e transporte florestal. Revista da Madeira, n.51, p.52-62, 2002.

R. Árvore, Viçosa-MG, v.31, n.6, p.1053-1061, 2007 
